\title{
Endothelial Cell, Pericyte, and Perivascular Resident Macrophage-Type Melanocyte Interactions Regulate Cochlear Intrastrial Fluid-Blood Barrier Permeability
}

\author{
Lingling Neng, ${ }^{1}$ Fei Zhang, ${ }^{1}$ Allan Kachelmeier, ${ }^{1}$ and Xiaorui Shi ${ }^{1}$ \\ ${ }^{1}$ Oregon Hearing Research Center, Department of Otolaryngology/Head Ev Neck Surgery, Oregon Health Ev Science University, \\ 3181 SW Sam Jackson Park Road, 97239-3098, Portland, OR, USA
}

Received: 21 August 2012; Accepted: 27 November 2012; Online publication: 18 December 2012

\begin{abstract}
The integrity of the fluid-blood barrier in the stria vascularis is critical for maintaining inner ear homeostasis, especially for sustaining the endocochlear potential, an essential driving force for hearing function. However, the mechanisms that control intrastrial fluid-blood barrier permeability remain largely unknown. At the cellular level, the intrastrial fluid-blood barrier comprises cochlear microvascular endothelial cells connected to each other by tight junctions (TJs), an underlying basement membrane, and a second line of support consisting of cochlear pericytes and perivascular resident macrophage-type melanocytes. In this study, we use a newly established primary cell culture-based in vitro model to show that endothelial cells, pericytes, and perivascular resident macrophage-type melanocytes interact to control intrastrial fluid-blood barrier permeability. When the endothelial cell monolayer was treated with pericyte-or perivascular resident macrophage-type melanocyte-conditioned media, the permeability of the endothelial cell monolayer was significantly reduced relative to an untreated endothelial cell monolayer. Further study has shown the pericytes and perivascular resident macrophage-type melanocytes to regulate $\mathrm{TJ}$ expression in the endothelial cell monolayer. The new cell culture-based in vitro model offers a unique opportunity to obtain information on the organ-specific characteristics of the cochlear
\end{abstract}

Correspondence to: Xiaorui Shi - Oregon Hearing Research Center, Department of Otolaryngology/Head \& Neck Surgery • Oregon Health \& Science University 3181 SW Sam Jackson Park Road, 97239-3098, Portland, OR, USA. Telephone: +1 503494 7149; fax: +15034945656; shix@ohsu.edu blood/tissue barrier. Our finding demonstrates the importance of signaling among pericytes, endothelial cells, and perivascular resident macrophage-type melanocytes to the integrity of the intrastrial fluid-blood barrier.

Keywords: endothelial cell, pericyte, perivascular resident macrophages-type melanocyte, primary cell line, paracellular permeability, mouse cochlea

\section{INTRODUCTION}

Integrity of the intrastrial fluid-blood barrier is critical for solute homeostasis and prevention of the influx of toxic substances (Juhn and Rybak 1981; Juhn et al. 2001). ${ }^{1}$ Loss of intrastrial fluid-blood barrier integrity, with concomitant vascular permeability, results in cochlear edema in the stria vascularis. Cochlear edema is thought to be present in a number of hearing disorders, including autoimmune inner ear disease, noise-induced hearing loss, and several genetically linked diseases (McMenomey et al. 1992; Cohen-Salmon et al. 2007; Klein et al. 2008; Kellerhals 1972; Hukee and Duvall 1985; Suzuki et al. 2002; Shi 2009). Recent progress in understanding the physiology of the blood-brain barrier (BBB) and bloodretinal barrier (BRB) provides useful insight into the largely unknown and poorly understood mechanisms that control endothelial blood-barrier permeability in the stria vascularis. Gaps in our understanding of the intrastrial fluid-blood barrier significantly limit development of effective drug therapies for vascular 
dysfunction-related hearing loss. Targeting dysfunctions, which involve maintenance of the endolymphatic potential, is particularly important.

In the classical view, the intrastrial fluid-blood barrier at the cellular level comprises microvascular endothelial cells lining cochlear microvessels and closely associated basement membrane (Juhn 1988; Juhn and Rybak 1981; Juhn et al. 1981). The capillary endothelium is characterized by presence of tight junctions (TJ), lack of fenestrations, and a minimal number of pinocytotic vesicles. In particular, TJs between the strial endothelial cells form a diffusion barrier, which selectively excludes most blood-borne substances from entering the ear, protecting it from systemic influences (Juhn 1988; Juhn and Rybak 1981; Juhn et al. 1981; Salt et al. 1987; Takeuchi et al. 2001). However, recent studies from our lab reveal the intrastrial fluid-blood barrier to include not only endothelial cells and basement membrane but also a large number of pericytes and perivascular resident macrophage-type melanocytes (Shi 2010; Shi et al. 2008; Dai et al. 2010). ${ }^{2}$ The three component cells are connected by the extracellular basement membrane (see the illustration in Fig. 1). Pericytes closely oppose the endothelial cells, with basement membrane interposed between them (Shi 2009). Perivascular resident macrophage-type melanocytes ensheath the vessel wall and have end-feet that tightly envelope the endothelium. The complexity of the morphology is mirrored in the physiology. In particular, our findings suggest a new model of the intrastrial fluid-blood barrier is needed, one which incorporates this complexity and includes the interaction between pericytes, perivascular resident macrophage-type melanocytes, and basement membrane. While function has yet to be thoroughly described for all these

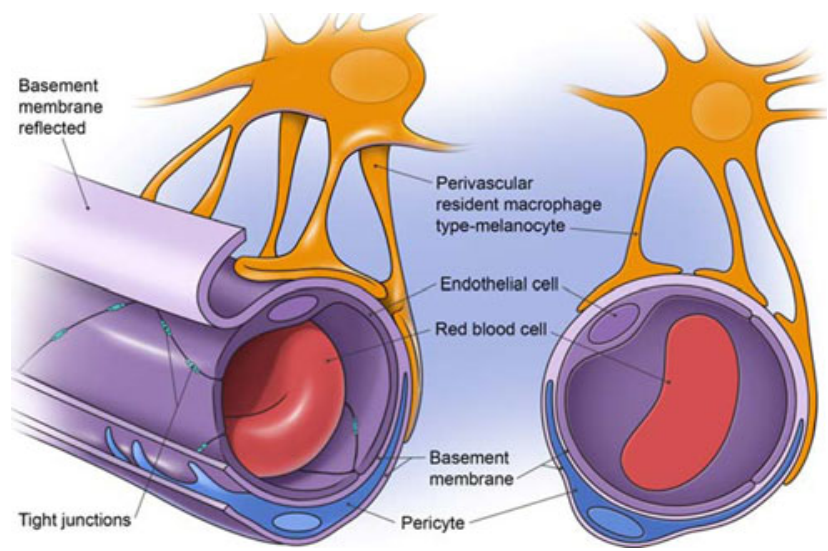

FIG. 1. The illustration of a cochlear microvessel in cross-section shows the major components of the intrastrial fluid--blood barrier. The vessel lumen is comprised of endothelial cells connected by TJs. Endothelial cells are ensheathed by a dense basement membrane shared with pericytes. Perivascular resident macrophage-type melanocyte end-feet cover a large portion of the capillary surface. cell types, the role of pericytes in the intrastrial fluidblood barrier is particularly elusive. In the brain, pericytes and glial cells are known to have essential roles in regulation of barrier integrity and tissueoriented functions (Armulik et al. 2010; Cardoso et al. 2010). Barriers without these cells lose tight junction proteins, become leaky, and are associated with tissue edema (Al Ahmad et al. 2009). In an earlier study, we showed perivascular resident macrophage-type melanocytes (morphologically similar to astrocytes and glial cells in the brain) to be the essential cell type regulating intrastrial fluid-blood barrier permeability (Zhang et al. 2012).

Pericyte-endothelial interactions, known to be a particularly salient feature of the blood-brain barrier, profoundly affect basement membrane and endothelial tight junction structure and function (Liu et al. 2012). In an earlier study, we showed pericytes to densely populate the surface of capillaries in the stria vascularis (Shi et al. 2008). However, the role of pericytes in vascular stability has not been determined.

In this study, we used a new cell culture-based in vitro model to directly study the signaling between endothelial cells, pericytes, and perivascular resident macrophage-type melanocytes. The aim is to determine the specific contribution of each phenotype to intrastrial fluid-blood barrier integrity and obtain information on the organ-specific characteristics of the cochlear blood/tissue barrier.

\section{MATERIALS AND METHODS}

\section{Animals}

C57BL/6J (aged 10-15 days) mice were obtained by the use of inbred C57BL/6J mice purchased from Jackson Laboratory (Bar Harbor, ME, USA). The protocol for the care and use of these animals was approved by the Institutional Animal Care and Use Committee at Oregon Health \& Science University (IACUC approval number B11265).

\section{Primary cell culture}

Protocols for generating the three primary cell lines used in these experiments were previously reported (Zhang et al. 2012). Briefly, cochleae from 10- to 15day-old C57BL/6J mice were harvested under sterile conditions. The stria vascularis was gently pulled away from the spiral ligament and placed in ice-cold perilymph solution containing $125 \mathrm{mmol} / \mathrm{L} \mathrm{NaCl}$, $3.5 \mathrm{mmol} / \mathrm{L} \mathrm{KCl}, 1.3 \mathrm{mmol} / \mathrm{L} \mathrm{CaCl} 2,1.5 \mathrm{mmol} / \mathrm{L}$ $\mathrm{MgCl}_{2}, 0.51 \mathrm{mmol} / \mathrm{L} \mathrm{NaH}{ }_{2} \mathrm{PO}_{4}, 10 \mathrm{mmol} / \mathrm{L}$ HEPES, and $5 \mathrm{mmol} / \mathrm{L}$ glucose at $\mathrm{pH} 7.4$ with osmolarity adjusted to $310 \mathrm{mmol} / \mathrm{kg}$. The isolated stria vascularis was washed with gentle shaking in cool perilymph 
solution for $10 \mathrm{~min}$ and transferred to a clean $35-\mathrm{mm}$ collagen I coated dish with $2 \mathrm{ml}$ of cell culture medium. The stria vascularis was cut into small pieces with sterile ophthalmic tweezers under a dissection microscope. Fragmented pieces of the stria vascularis were seeded around the dish to roughly uniform density. The procedure for situating the fragments requires approximately $2 \mathrm{~h}$. The medium is changed every 3 days. The cells are incubated at $37^{\circ}$ in $5 \%$ $\mathrm{CO}_{2}$ for 7-14 days until the cell clones melt. Cell clusters of each phenotype are visible by phase contrast microscopy at 6-7 days, at which time the cells are passaged into a $60-\mathrm{mm}$ collagen I coated dish. Pericytes were cultured in Dulbecco's modified Eagle's medium (DMEM low glucose, Invitrogen, USA) containing $10 \%$ fetal bovine serum (FBS, Sigma, USA), $100 \mathrm{nM}$ pigment epithelium-derived factor (PEDF), and $1 \%$ penicillin/streptomycin solution $(10,000 \mathrm{U}$ penicillin and $10 \mathrm{mg}$ streptomy$\mathrm{cin} / \mathrm{ml}$, Sigma, USA). Endothelial cells were cultured in CS-C medium (Sigma, USA) containing $10 \%$ fetal bovine serum (FBS, Sigma, USA), $1 \%$ endothelial cell growth factor (Sigma, USA), and $1 \%$ penicillin/ streptomycin solution $(10,000 \mathrm{U}$ penicillin and $10 \mathrm{mg}$ streptomycin/ml, Sigma, USA), and perivascular resident macrophages in medium 254CF (Invitrogen, USA) containing $1 \%$ human melanocyte growth supplement (Invitrogen, USA), $10 \%$ FBS (Sigma, USA), and $0.2 \%$ gentamicin/amphotericin B solution (Sigma, USA).

\section{Cell purification with flow cytometry}

The cultured cells were purified by fluorescenceactivated cell sorting with a BD influx cell sorter operated at 45 psi using a $70-\mu \mathrm{m}$ nozzle. First, the cultured cells were detached from the dish with a $0.25 \%$ trypsin-EDTA solution (Sigma, USA). The cells were gently washed in $2 \mathrm{ml}$ of their culture medium, placed in a $12 \times 75 \mathrm{~mm}$ polypropylene FACS tube, and centrifuged $\left(300 \times g, 5 \mathrm{~min}, 4^{\circ} \mathrm{C}\right)$. Cells $\left(1 \times 10^{6}\right.$ cells/ $\mathrm{ml}$ ) were incubated with marker antibodies for $30 \mathrm{~min}$ in the dark at $4{ }^{\circ} \mathrm{C}$, followed by $2 \mathrm{ml}$ of their cultured medium to wash the cells, and centrifuged $(300 \times g$, $5 \mathrm{~min}, 4{ }^{\circ} \mathrm{C}$ ). After discarding the supernatant, the cells were resuspended in culture medium to a concentration of $1 \times 10^{6}$ cells $/ \mathrm{ml}$. Phycoerythrin-conjugated rat monoclonal antibody labeling for plateletderived growth factor beta receptor (Abcam, USA) at a concentration of $0.5 \mu \mathrm{g} / \mathrm{ml}$ was used to identity pericytes in sorting. Rat IgG phycoerythrin (Abcam, USA) at a concentration of $0.2 \mu \mathrm{g} / \mathrm{ml}$ served as the isotype control label. The endothelial cells were identified with fluorescein isothiocyanate (FITC)-conjugated isolectin B4 (BSI-B4) (Sigma, USA) at a concentration of $20 \mu \mathrm{g} / \mathrm{ml}$, with cells in $0.2 \mathrm{M}$ galactose (Sigma, USA) preincubated with lectin serving as the control. Perivascular resident macrophage-type melanocytes were identified with a phycoerythrin-conjugated rat monoclonal antibody for F4/ 80 (Abcam, USA) at a concentration of $10 \mu \mathrm{l} / 10^{6}$ cells (in $100 \mu \mathrm{l}$ ), with cells labeled by rat IgG phycoerythrin (Abcam, USA) at a concentration of $0.2 \mu \mathrm{g} / \mathrm{ml}$ serving as the isotype control. Positive cells from sorting were collected in culture media and plated on $60 \mathrm{~mm}$ collagen I coated dishes.

\section{Cell validation}

Sorted cells were validated with antibodies for proteins that detected marker genes from the sorted cell DNA. In this study, aliquots of each cell phenotype were grown on 35-mm collagen-coated glass bottom dishes and labeled for immunohistochemical confirmation of specific markers including anti-von Willebrand factor (vWF) for endothelial cells, anti-F4/80 and anti-GST $\alpha 4$ for perivascular resident macrophages, and anti-desmin and anti-NG2 for pericytes.

\section{Immunohistochemistry and fluorescence microscopy}

The cochleae were isolated, harvested, and fixed in $4 \%$ paraformaldehyde overnight at $4{ }^{\circ} \mathrm{C}$, and rinsed in $37^{\circ} \mathrm{C}$ phosphate-buffered saline (PBS; pH7.2) to remove any residual $4 \%$ paraformaldehyde. Immunohistochemistry was performed as described previously (Rauch and Reale 1968). Tissue samples were permeabilized in $0.5 \%$ Triton X-100 (Sigma, St. Louis, MO, USA) for $0.5 \mathrm{~h}$ and immunoblocked with a solution of $10 \%$ goat serum and $1 \%$ bovine serum albumin in $0.02 \mathrm{~mol} / \mathrm{l} \mathrm{PBS}$ for an additional hour. The specimens were incubated overnight at $4{ }^{\circ} \mathrm{C}$ with the primary antibodies (listed in Table 1) in PBSbovine serum albumin. After three washes in PBS, the samples were incubated with secondary antibodies, either Alexa Fluor 568-conjugated goat anti-rabbit (catalog number A21069, Invitrogen, Eugene, OR, USA), Fluor 647-conjugated goat anti-rabbit (catalog number A-21244, Invitrogen, Eugene, OR, USA), or Alexa Fluor 568-conjugated goat anti-rat (catalog A11077 , Invitrogen, Eugene, OR, USA), for $1 \mathrm{~h}$ at room temperature. After three washes in PBS, the tissues were mounted in mounting medium (H-1000; Vector Laboratories, Inc., Burlingame, CA, USA) and visualized under an FV1000 Olympus laser-scanning confocal microscope. Controls were prepared by replacing primary antibodies with PBS. 3D rendering of confocal data was performed using the image processing functions in Fiji (http://fiji.sc/wiki/index.php/Fiji) and UCSF Chimera (Resource for Biocomputing, Visualization, and Informatics; http://www.cgl.ucsf.edu/ 
TABLE 1

Primary antibodies employed

\begin{tabular}{|c|c|c|c|c|c|}
\hline \multicolumn{6}{|c|}{ Primary antibodies employed } \\
\hline $\begin{array}{l}\text { Primary } \\
\text { antibodies }\end{array}$ & $\begin{array}{l}\text { Vectors } \\
\text { lidentification }\end{array}$ & $\begin{array}{l}\text { Catalog } \\
\text { number }\end{array}$ & Dilution source & & Specificity \\
\hline VE-cadherin & Abcam & Ab33168 & $\begin{array}{l}1: 50 \text { (dilution with } \\
1 \% \text { BSA-PBS) }\end{array}$ & $\begin{array}{l}\text { Rabbit polyclonal } \\
\text { antibody to VE Cadherin }\end{array}$ & Reacts with $\mathrm{Ms}, \mathrm{Ch}, \mathrm{Hu}$ \\
\hline ZO-1 & Invitrogen & $61-7300$ & $\begin{array}{l}1: 50 \text { (dilution with } \\
1 \% \text { BSA-PBS) }\end{array}$ & $\begin{array}{l}\text { Rabbit polyclonal } \\
\text { antibody to ZO-1 }\end{array}$ & $\begin{array}{l}\text { Reacts with Ms, Hu, } \\
\text { Rat, Gp }\end{array}$ \\
\hline $\mathrm{F} 4 / 80$ & eBioscience & $14-4801-85$ & $\begin{array}{l}\text { 1:50 (dilution with } \\
1 \% \text { BSA-PBS) }\end{array}$ & $\begin{array}{l}\text { Rat monoclonal } \\
\text { antibody to F4/80 }\end{array}$ & Reacts with Ms \\
\hline GST $\alpha 4$ & Santa Cruz & Sc-241483 & $\begin{array}{l}1 ; 100 \text { (dilution with } \\
1 \% \text { BSA-PBS) }\end{array}$ & $\begin{array}{l}\text { Goat polyclonal antibody } \\
\text { to GST } \alpha 4\end{array}$ & Reacts with Ms, Hu \\
\hline $\begin{array}{l}\text { von Willebrand } \\
\text { Factor }\end{array}$ & Abcam & Ab11713 & $\begin{array}{l}1: 100 \text { (dilution with } \\
1 \% \text { BSA-PBS) }\end{array}$ & $\begin{array}{l}\text { Sheep polyclonal to } \\
\text { von Willebrand factor }\end{array}$ & $\begin{array}{l}\text { Reacts with Ms, } \\
\text { Hu, Pig }\end{array}$ \\
\hline Desmin & Abcam & Ab32362 & $\begin{array}{l}1: 100 \text { (dilution with } \\
1 \% \text { BSA-PBS) }\end{array}$ & $\begin{array}{l}\text { Rabbit monoclonal } \\
\text { to desmin }\end{array}$ & $\begin{array}{l}\text { Reacts with Ms, } \\
\text { Rat, Gp, Hu }\end{array}$ \\
\hline NG2 & Abcam & Ab83508 & $\begin{array}{l}1: 100 \text { (dilution with } \\
1 \% \text { BSA-PBS) }\end{array}$ & $\begin{array}{l}\text { Mouse monoclonal } \\
\text { to NG2 }\end{array}$ & Reacts with Ms, Hu \\
\hline
\end{tabular}

chimera/) for visualization, analysis, and presentation. Individual channels were split and converted into separate image stacks, which were then filtered to reduce the signal/noise ratio. Volume data were displayed at respective thresholds as solid or partially transparent isosurfaces in UCSF Chimera using the volume viewer.

\section{Triple labeling}

To visualize the morphology of the intrastrial fluidblood barrier, we triple-labeled lateral-wall tissues, adding antibody for desmin to identify pericytes (Abcam) and antibody for F4/80 to identify perivascular resident macrophage-like melanocytes (eBioscience), to cochlear capillary endothelial cells prelabeled with the fluorescent dye 1,1-dioctadecyl3,3,3,3-tetramethylindocar bocyanineperchlorate, Dil (Dai and Shi 2011). The procedure for immunohistochemical labeling of desmin and F/80 was the same as described above.

\section{Characterization of the endothelial cell monolayer}

Confluent monolayers of endothelial cells are characterized by low endothelial monolayer permeability to FITC-dextran and by expression of tight junction proteins such as ZO-1 and VE-cadherin (Zhang et al. 2012).

\section{Production of conditioned media}

DMEM (Life Technologies, USA) containing $10 \%$ FBS (Sigma, USA) and $1 \%$ penicillin-streptomycin solution (10,000 $\mathrm{U}$ of penicillin and $10 \mathrm{mg}$ streptomy$\mathrm{cin} / \mathrm{ml}$ ) (Sigma, USA) was used as a starter general culture medium (CM). To obtain pericyte or perivas- cular resident macrophage-type melanocyte conditioned media, $5 \times 10^{5}$ pericytes or $5 \times 10^{5}$ perivascular resident macrophage-type melanocytes were cultured in a $60 \mathrm{~mm}$ cell culture dish with $\mathrm{CM}$ at $37^{\circ} \mathrm{C}$ in a $5 \%$ $\mathrm{CO}_{2}$ incubator. After 3 days of cultivation, the supernatant of the culture was decanted. Debris was removed by centrifugation at $550 \times g$ for $5 \mathrm{~min}$. The supernatants (conditioned media) were aliquoted and stored at $-20{ }^{\circ} \mathrm{C}$ until use.

\section{Cell culture for the coculture model}

Five different culture models (one control model and four experimental models) were developed in this study. For the control group, purified endothelial cells at passage 3 at a density of $4 \times 10^{4} / \mathrm{cm}^{2}$ were seeded and grown on the polyethylene terephthalate membranes of Transwell inserts (BD Biosciences, catalog number 353096) overnight. In all cases, endothelial cells monolayers were not formed by overnight growth. All experimental groups were seeded with endothelial cells at the same passage number and density $\left(4 \times 10^{4} / \mathrm{cm}^{2}\right)$ and grown on the inserts for 5 days. Treatment in experimental model 1 was with $4 \mathrm{ml} \mathrm{CM}$, experimental model II with $2 \mathrm{ml}$ $\mathrm{CM}$ and $2 \mathrm{ml} \mathrm{PC}$ conditioned medium, experimental model III with $2 \mathrm{ml} \mathrm{CM}$ and $2 \mathrm{ml}$ perivascular resident macrophage-type melanocyte conditioned medium, and experimental model IV with $2 \mathrm{ml}$ pericyte conditioned medium and $2 \mathrm{ml}$ perivascular resident macrophage-type melanocyte conditioned medium.

\section{Assessment of endothelial monolayer permeability}

Transendothelial permeability of the endothelial cell monolayer to FITC-dextran (MW, $70 \mathrm{kDa}$ ) was 
measured according to the manufacturer's instructions (catalog number ECM644, vascular permeability assay kit; Millipore, Billerica, MA, USA) and described in our previous study (Zhang et al. 2012). Briefly, the small fluorescent molecule (diluted at 1:40 with medium) permeates through the monolayer into the basolateral chamber. The amount of dextran accumulating in the basolateral chamber is an indicator of the permeability of the endothelial cell layer. Permeability of the endothelial cell monolayer was assessed as FITC-dextran fluorescence with a multiwell microplate reader (TECAN GENios ELISA reader, Tecan Group Ltd.) at excitation/emission wavelengths of $485 / 535 \mathrm{~nm}$.

\section{Statistics}

All statistical analyses were performed using GraphPad Prism 5.0. Data, presented as means \pm $\mathrm{SD}$, were evaluated using one-way ANOVA followed by a Tukey's multiple comparison test $(\alpha$ level= 0.05 in all cases) for comparisons of three or more groups.

\section{RESULTS}

Morphology of the intrastrial fluid-blood barrier

The three major cell types of the intrastrial fluidblood barrier are endothelial cells, pericytes, and perivascular resident macrophage-type melanocytes. A maximum projection reconstructed from a zstack of confocal microscope images (Fig. 2A) shows the overall morphology of the three cellular components in the barrier. Endothelial cells were labeled with fluorescent Dil. Perivascular resident macrophage-type melanocytes were immunolabeled for $\mathrm{F} 4 / 80$, and pericytes for desmin. The images clearly show the intrastrial fluid-blood barrier covered by a large population of accessory cells, which include pericytes and perivascular resident macrophage-type melanocytes. Figure $2 \mathrm{~B}$ is an isosurface rendering of the confocal z-stacks, and Fig. 2C, a close-up image, further details the structure of the intrastrial fluid-blood barrier.

Production and validation of the barrier component cell lines

Endothelial cell, pericyte, and perivascular resident macrophage-type melanocyte primary cell lines (Figs. 3A-C) generated by the previously described method (Zhang et al. 2012) were validated for phenotype by immunohistochemical analysis (Figs. 3D-F).
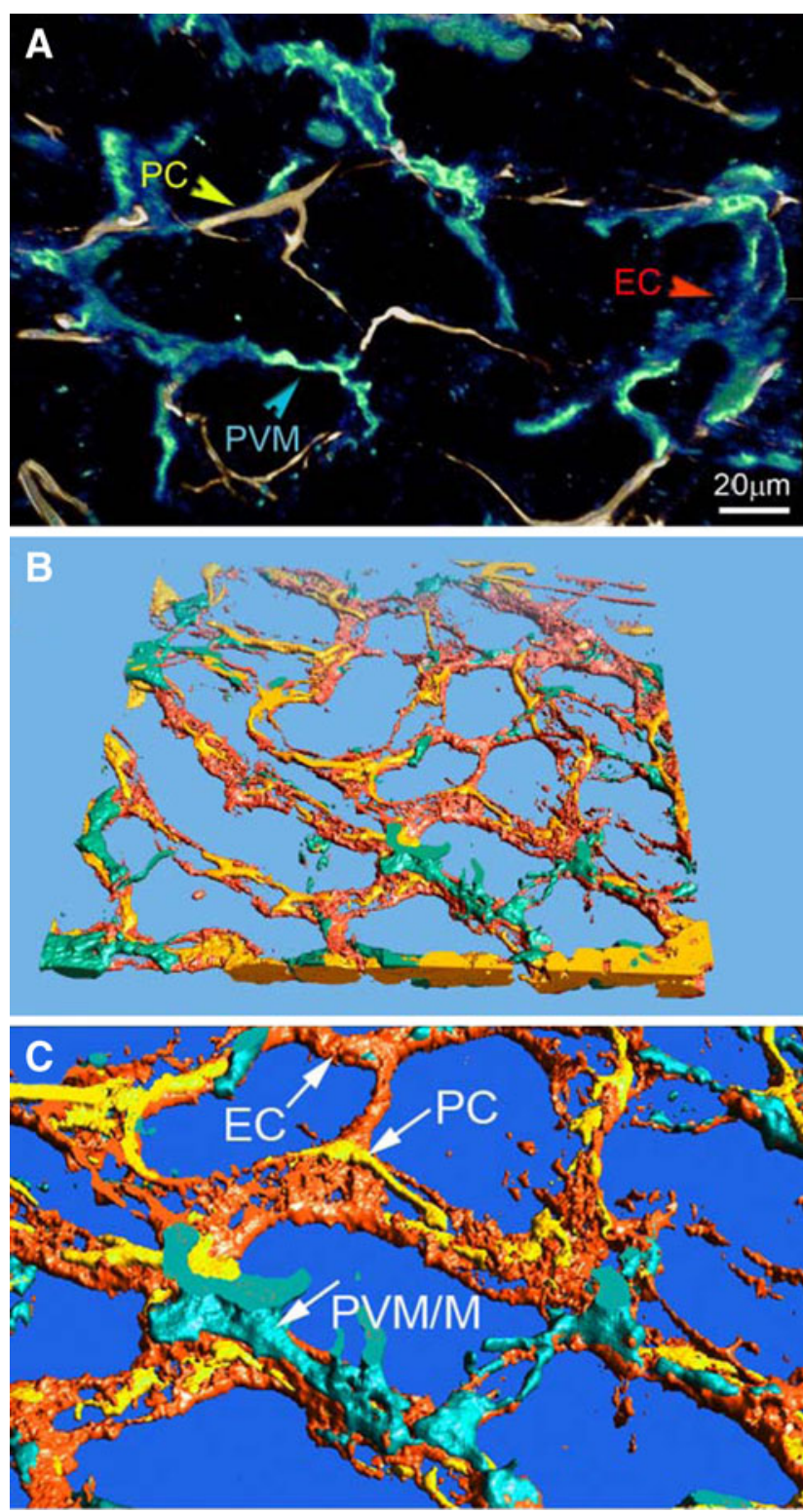

FIG. 2. Cellular conformation of the intrastrial fluid-blood barrier. A The reconstructed confocal microscope image of the intrastrial fluid-blood barrier highlights the morphological complexity that underlies interactions between endothelial cells, pericytes, and perivascular resident macrophage-type melanocytes. The perivascular resident macrophage-type melanocytes were immunolabeled for $\mathrm{F} 4 / 80$, pericytes for desmin, and endothelial cells with fluorescent Dil. B, C Isosurface renderings which give perspective on the interface between ramified processes of perivascular resident macrophage-type melanocytes, endothelial tube, and pericytes.

\section{Verification of a functional endothelial monolayer}

The endothelial monolayer was verified as expressing several cell-cell tight junction proteins, including ZO-1 (Fig. 4A) and VE-cadherin (Fig. 4B). Permeability was assessed by measuring the flux of $70 \mathrm{kDa}$ fluorescent dextran across the endothelial 

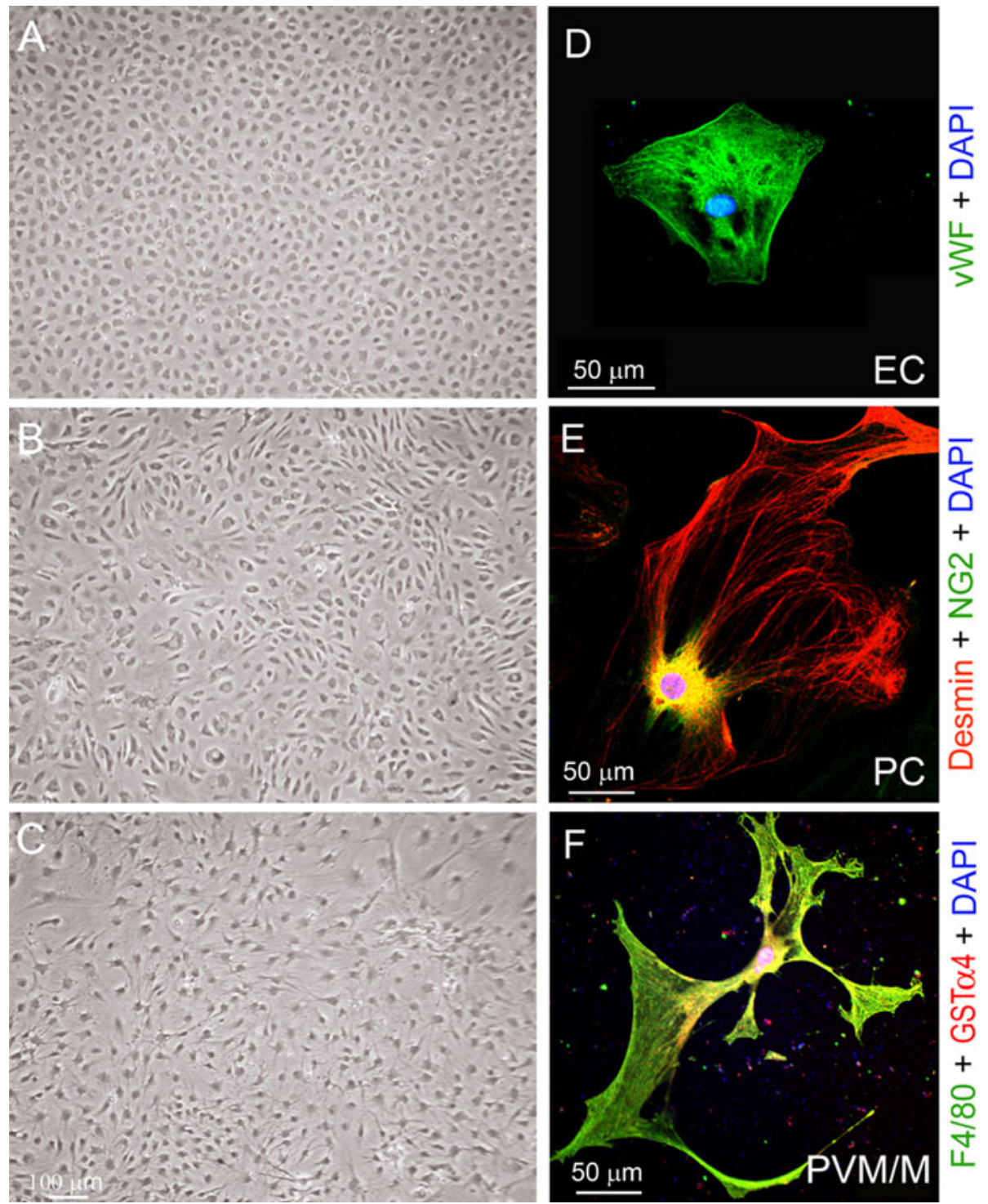

FIG. 3. Production and validation of the endothelial cell, pericyte, and perivascular resident macrophage-type melanocyte primary cell lines. A-C Images of cultured endothelial cell, pericyte, and perivascular resident macrophage-type melanocytes at the third passage. D Endothelial cells double-labeled for vWF (green) and nuclei (blue). E pericytes are triple-labeled for Desmin (red), NG2 (green), and nuclei (blue). F Perivascular resident macrophage-type melanocytes triple-labeled for F4/80 (green), GSTa4 (red), and nuclei (blue).
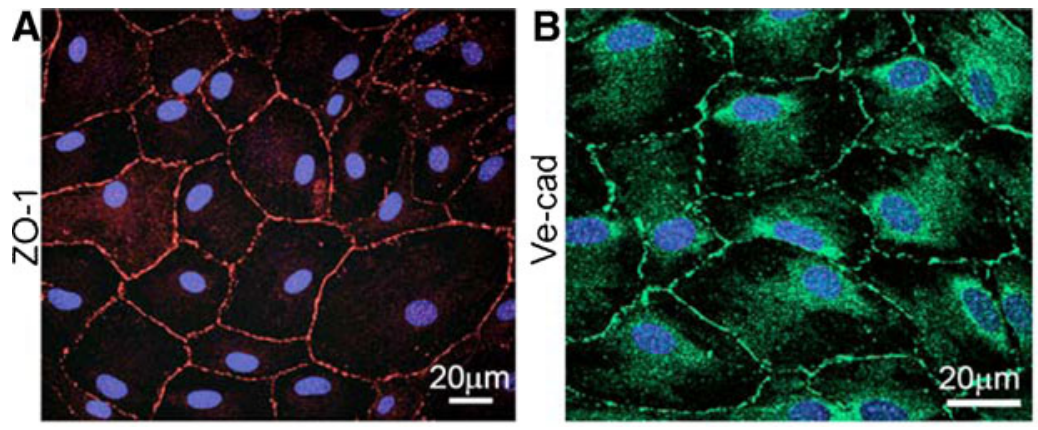

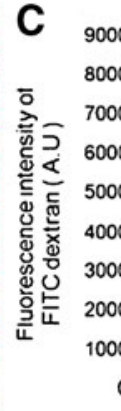

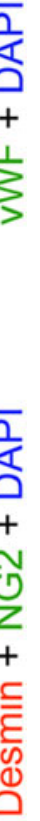

FIG. 4. Verification of a functional endothelial cell monolayer. A The endothelial cells are double labeled for the tight junction protein ZO-1 (green) and nuclei (b/ue). B The endothelial cells are double labeled for the tight junction protein VE-cadherin (green) and nuclei (blue). C FITC-dextran fluorescence intensity is shown at different time points. The endothelial cell monolayer is established by day 5 . 
cell monolayer (illustrated in Fig. 4C). The degree of endothelial cell monolayer leakage was determined from the intensity of FITC-dextran fluorescence in the basolateral chamber.

Pericyte and perivascular resident macrophage-type melanocyte secretions affect the integrity of intrastrial fluid-blood barrier

Treatment with pericyte, or perivascular resident macrophage-type melanocyte, conditioned media increases the permeability of endothelial cell monolayers. Permeability was assessed by comparing the transport of $70 \mathrm{kDa}$ fluorescent dextran across the endothelial cell monolayer relative to a control model (null-endothelial cell monolayer) in each of the four confluent endothelial cell monolayer models illustrated in Fig. 5A. The degree of endothelial cell monolayer leakage was determined by measuring the intensity of FITC-dextran fluorescence in the basolateral chamber (Fig. 5B). Our results show permeability of the endothelial cell monolayer to markedly decrease in pericyte, perivascular resident macrophage-type melanocyte, or pericyte+perivascular resident macrophage-type melanocyte, conditionedmedium-treated endothelial cell monolayers compared to a control endothelial cell monolayer not treated with conditioned media [Fig. 5B, $F(3,20)=20.58, p<0.001$; $\left.p_{(\mathrm{PC} \text { vs EC) }}<0.05, p_{\text {(PVM vs EC) }}<0.05, p_{\text {(PC+PVM vs EC) }}<0.05\right]$. The result indicates that signaling between endothelial cells, pericytes, and perivascular resident macrophage- type melanocytes strengthens the integrity of the endothelial barrier.

Pericyte and perivascular resident macrophage signaling affects expression of TJ proteins in the intrastrial fluid-blood barrier

We next examined expression of tight junctions, the mechanism by which pericytes and perivascular resident macrophage-type melanocytes control the permeability of the intrastrial fluid-blood barrier. The tightness of the blood barrier is attributable to TJs expressed by endothelial cells (Rubin and Staddon 1999). The major tight junction-associated proteins in the intrastrial fluidblood barrier are occludin, claudins, $\mathrm{ZO}$, and adherens junction proteins (Kitajiri et al. 2004a,b; Gow et al. 2004; Yang et al. 2011). In this study, we assessed whether expression of TJ protein paralleled the effect of pericyte and perivascular resident macrophage-type melanocyte derived conditioned media on barrier permeability. With quantitative real-time PCR and western analysis we found that messenger RNA (mRNA) levels for $Z O-1$ and vecadherin in the presence and absence of perivascular resident macrophage-type melanocytes are significantly different. $Z O-1$ [Fig. 6A, $F(3,20)=19.32, p<0.001$; $p_{(\mathrm{PC} \text { vs EC) }}<0.05, p_{(\mathrm{PVM} / \mathrm{M} \text { vs EC) }}<0.05, p_{(\mathrm{PC}+\mathrm{PVM} / \mathrm{M} \text { vs EC) }}<$ 0.05 ] and vecadherin [ Fig. $6 \mathrm{~A}, F(3,20)=33.04, p<0.001$; $p_{(\mathrm{PC} \text { vs EC) }}<0.05, p_{(\mathrm{PVM} / \mathrm{M} \text { vs EC) }}<0.001, p_{(\mathrm{PC}+\mathrm{PVM} / \mathrm{M} \text { vs EC) }}<$ $0.001]$ were dramatically increased in the conditionedmedia-treated endothelial cell monolayers. Concurrent with increased mRNA expression, protein levels for ZO-

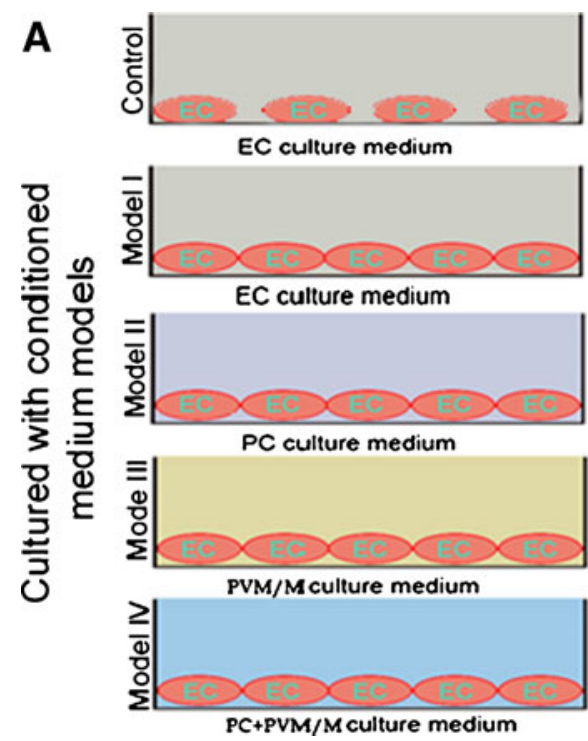

FIG. 5. Endothelial cell monolayers in vitro are more permeable in the absence of pericytes and perivascular resident macrophage-type melanocytes. A Treatment of an endothelial cell monolayer with different conditioned growth media. B The graph shows quantitative analysis of endothelial monolayer permeability under pericyte, perivascular resident macrophage-type melanocyte, and pericyte+

B

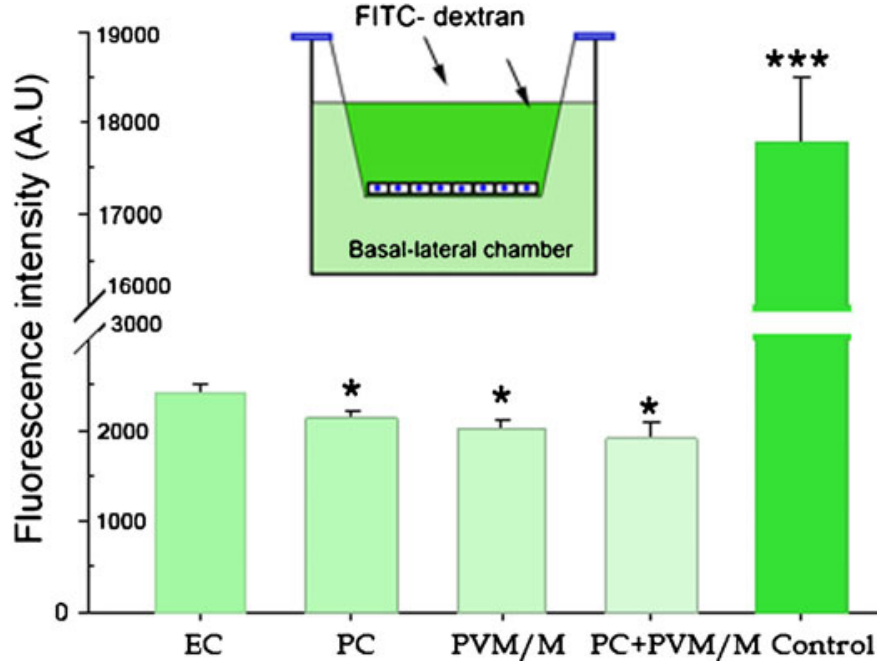

perivascular resident macrophage-type melanocyte, conditioned media treated conditions. Endothelial cell monolayer permeability is increased in monolayers not treated with the pericyte or perivascular resident macrophage-type melanocyte conditioned media. 

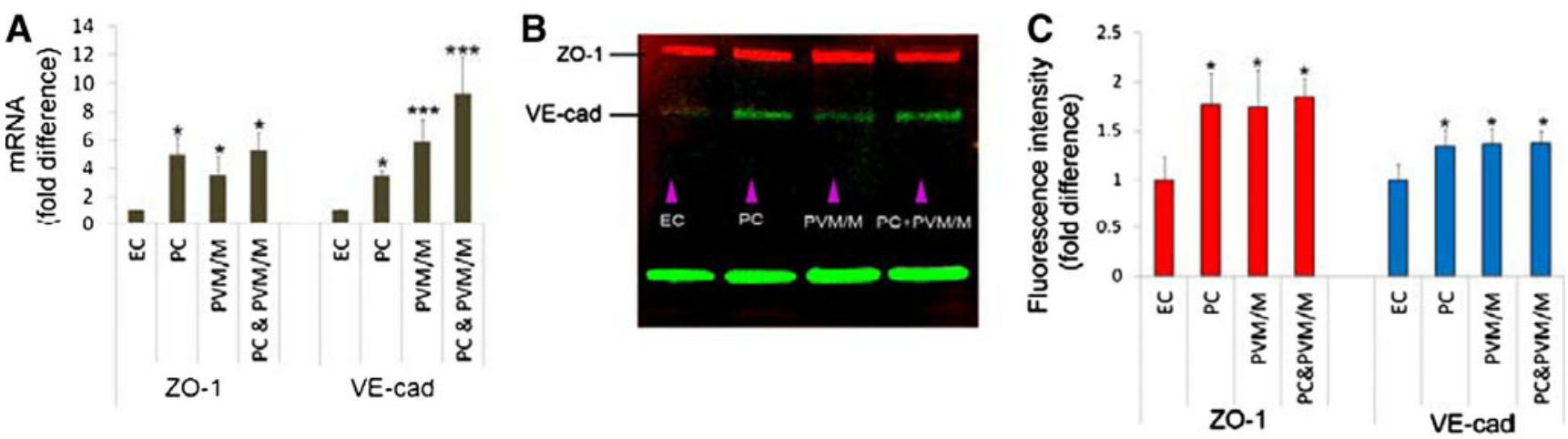
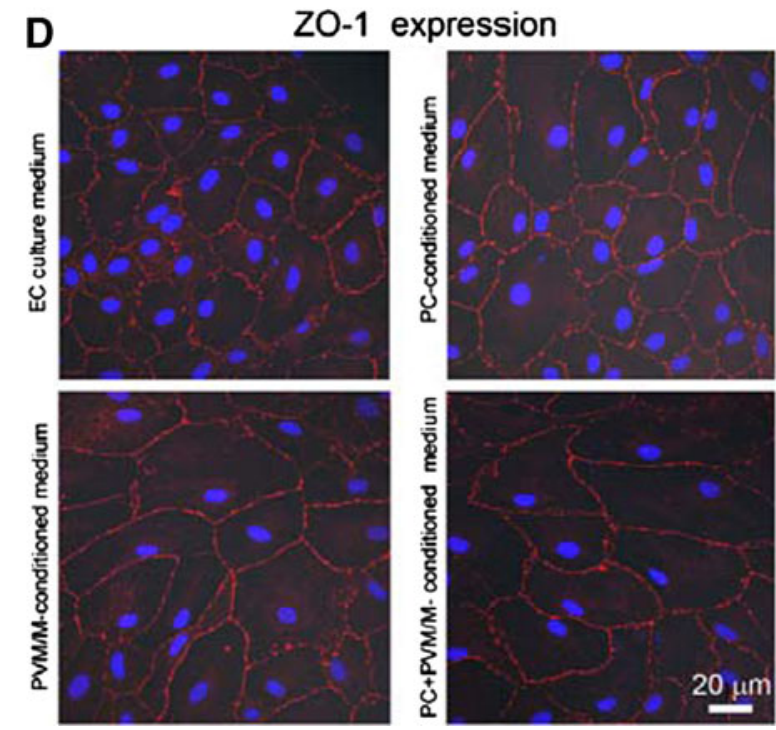

FIG. 6. Pericytes and PVMs control barrier integrity by affecting expression of TJ proteins. A Quantitative real-time PCR shows mRNA for zo-1 and ve-cadherin in the endothelial cell monolayer under different conditions. B Western protein analysis for ZO-1 and VEcadherin shows parallel trends. C The bar graph compares protein

1 and VE-cadherin, analyzed by Western blot, also showed a marked increase (Fig. 6B). Protein expression for ZO-1 [Fig. 6C, $F(3,32)=16.57, p<0.001 ; p_{(\mathrm{PC} \text { vs EC })}<$ $\left.0.05, p_{(\mathrm{PVM} / \mathrm{M} \text { vs EC) }}<0.05, p_{(\mathrm{PC}+\mathrm{PVM} / \mathrm{M} \text { vs EC) }}<0.05\right]$ and VE-cadherin $\left[F(3,32)=12.51, * * * p<0.001 ; * p_{(\mathrm{PC} \text { vs EC })}<\right.$ $\left.0.05, p_{(\mathrm{PVM} / \mathrm{M} \text { vs } \mathrm{EC})}<0.05, p_{(\mathrm{PC}+\mathrm{PVM} / \mathrm{M} \text { vs } \mathrm{EC})}<0.05\right]$. Furthermore, immunohistochemical examination by confocal microscopy clearly showed a more dense distribution of tight and adherens junction proteins with conditioned media treatment of the endothelial cells (Figs. 6D, E). We also noticed that endothelial cells are larger when the endothelial cells are treated with pericyte- and perivascular resident macrophage-type melanocyte conditioned media. The data indicate that secreted signals from either pericytes or perivascular resident macrophage-type melanocytes have an effect on the expression of TJs, directly linking pericytes and perivascular resident macrophage-type melanocytes with a mechanism, which accounts for the changes in endothelial barrier permeability.
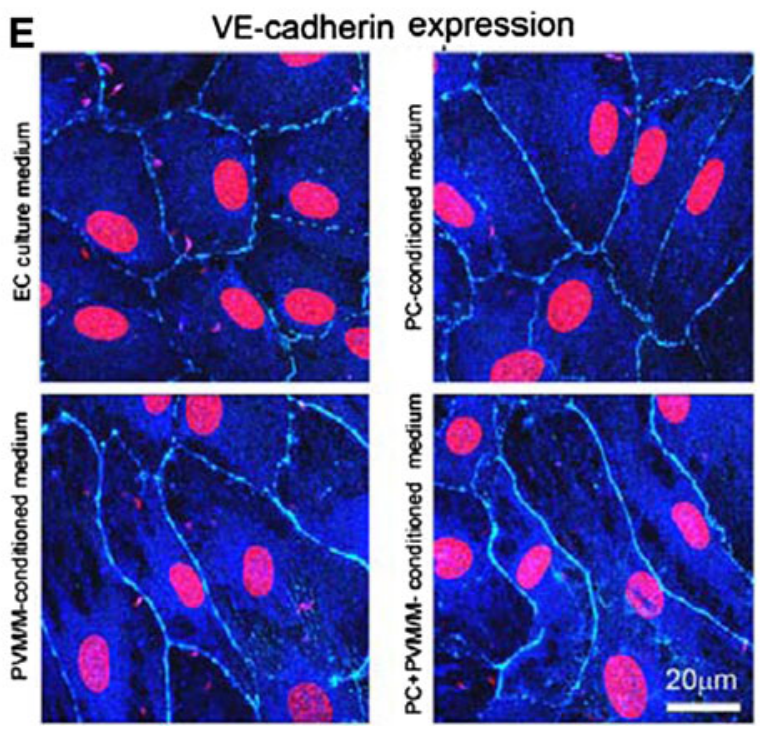

expression for ZO-1 and VE-cadherin in the presence and absence of pericyte or perivascular resident macrophage-type melanocytes. D, E Difference in protein expression is also reflected in immunofluorescent labeled ZO-1 and VE-cadherin.

\section{DISCUSSION}

Over the past few decades, in vitro cell-based models, widely used in BBB and BRB studies, have been powerful tools for investigating cell-cell interactions (Lamm et al. 1994; Rauch and Reale 1968; Shi 2010). Several different methods for isolating and culturing cells from the adrenal gland, umbilical vein, lung, skeletal muscle, and brain have been reported (Juhn et al. 1982; Sakagami et al. 1982, 1986, 1987; Juhn et al. 2001; Tagaya et al. 2011; Laurell et al. 2008). However, these methods have not been suitable for isolating intrastrial fluid-blood barrier cells. The methods used for capillary extraction and isolation on large tissue volumes have not been suitable for production of barrier component cells from the small volume, anatomically complex tissues of the inner ear. Our limited knowledge of the physiology of the cochlear blood barrier is 
partly the result of not having primary endothelial cells, pericytes, and perivascular resident macrophage-type melanocytes from the inner ear on which to experiment.

The signaling interactions between endothelial cells, pericytes, and perivascular resident macrophage-type melanocytes were investigated with in vitro models utilizing primary cell types. In particular, coculture of the cell types in various conformations of in vitro models provides the means to parse the signaling and identify the unique pericyte and perivascular resident macrophage-type melanocyte contribution to endothelial cell monolayer permeability.

In this study, using primary cell lines and coculture models, we found that strial pericytes secrete substances into the culture medium, which affect barrier properties, and subsequent treatment with pericyte secretion augmented medium "tightens" endothelial cell monolayer integrity (Fig. 5C). Consistent with our previous report (Zhang et al. 2012), signals from perivascular resident macrophage-type melanocyte secretion augmented culture media also affect endothelial barrier permeability in vitro.

TJs between adjacent endothelial cells physiologically explain the limited paracellular permeability of the intrastrial fluid-blood barrier. The permeability properties of the barrier reflect, to a major degree, the tightness of the intercellular junction. The major TJ proteins in the intrastrial fluid-blood barrier are occludin, claudins, zona occludens (ZOs), and adherens junction proteins (Kitajiri et al. 2004a; Yang et al. 2011). The TJ proteins are connected to the actin cytoskeleton by accessory/ anchoring proteins. In this study, we examined the TJ protein ZO-1, an important adaptor protein linking transmembrane junctional complexes to the underlying actin cytoskeleton, and VE-cadherin, an important adhesive protein known to tighten the intrastrial fluid-blood barrier.

Pericyte and perivascular resident macrophagetype melanocyte conditioned culture media increased expression of $\mathrm{TJ}$ proteins such as $\mathrm{ZO}-1$ and VE-cadherin in the endothelial cell monolayer at both the mRNA transcript and protein levels (Fig. 6). The data indicate secreted signals from pericytes and perivascular resident macrophagetype melanocytes cause increased expression of TJs, which accounts for the change in endothelial barrier permeability.

Our previous study showed the effect of perivascular resident macrophage-type melanocytes on intrastrial fluid-blood barrier integrity mediated by PEDF (Zhang et al. 2012). PEDF was shown to modulate expression of $\mathrm{TJ}$-associated proteins. We presume that the effective agent responsible for the upregulation of $\mathrm{TJs}$ by perivascular resident macrophage-type melanocyte conditioned medium is largely the secreted PEDF. However, other unknown signal molecules may also be contributing to $\mathrm{TJ}$ expression between endothelial cells.

The agent secreted by pericytes into the conditioned medium and responsible for the effect on $\mathrm{TJ}$ expression in endothelial cells is unknown. Also to be determined are interaction effects between the secretions of pericytes and perivascular resident macrophage-type melanocytes. Endothelial cell monolayers treated with a mixture of pericyte+perivascular resident macrophage-type melanocyte conditioned culture medium showed statistical differences in permeability relative to nontreated endothelial cell monolayers; however, no significant difference in endothelial cell monolayer permeability was found between pericyte+perivascular resident macrophagetype melanocyte conditioned culture medium treatment and separate treatment with either pericyte or perivascular resident macrophage-type melanocyte conditioned culture medium.

The intrastrial fluid-blood barrier in the cochlea is a dynamic interface that regulates the influx and efflux of substances, playing an important role in stabilizing the cochlear intrastrial space and sustaining the endocochlear potential. Many intrastrial fluidblood barrier dysfunction-related hemostatic imbalances have unknown causes. Is altered signaling between barrier component cells the root cause for some of cochlear hemostatic imbalance? How do pathological conditions such as ischemia, hypoxia, and inflammation in the cochlea affect cell-cell interactions? Knowledge of these interactions will facilitate development of new protective and restorative therapies for intrastrial fluid-blood barrier dysfunction-related hearing disorders that involve aberrant cell-cell signaling.

Taken together, our newly established in vitro coculture model provides the first evidence that cochlear pericytes and perivascular resident macrophage-type melanocytes have an important role in maintaining barrier integrity. Our findings show pericytes in the cochlea to contribute to barrier function in the stria vascularis similar to the way pericytes contribute to barrier function in the brain (Armulik et al. 2010) and retina (Kim et al. 2009). As in the brain and retina, absence of pericyte secretory signals increases endothelial cell permeability. A similar proximal mechanism is also found in the ear. Pericyte signaling to endothelial cells upregulates ZO-1 and VE-cadherin. The study confirms the essential cosignaling role of perivascular resident macrophage-type melanocytes to barrier integrity. 


\section{FOOTNOTE 1}

The term "blood-labyrinth barrier (BLB)" initially referred to a barrier between the blood and perilymph (Juhn et al. 1981; Juhn 1988). In recent years "BLB" has been less strictly applied to specialized capillary networks in the spiral ligament and stria vascularis (Suzuki et al. 1998, 2002; Schmutzhard et al. 2012). Occasionally, it has even been used to describe the fluid system in the vestibular system (Suzuki and Kaga 1999). In our early work, we used the term "BLB of the stria vascularis" to define our region of interest (Dai et al. 2010; Yang et al. 2011). However, the barrier that we study is situated between the blood flow and the intrastrial region of the stria vascularis. This region is critical for maintaining inner ear homeostasis, especially for maintaining the endolymphatic potential (EP), an essential driving force for hearing function. In order to convey this specificity, we use "intrastrial fluid-blood barrier" in the manuscript, following the wording of Cohen-Salmon et al. (2007) and a recent report from this lab by Zhang et al. (2012).

\section{FOOTNOTE 2}

In the standard view, the stria vascularis comprises three cell layers (from the inside: marginal, intermediate, and basal cell layers) and a rich capillary network. Are PVM/Ms a subclass of cells long called intermediate cells? In an earlier study, we found that a large population of perivascular cells in the intrastrial fluid-blood barrier of normal adult cochlea. We named the cells perivascular resident macrophages (PVMs), as they are positive for several macrophage surface molecules including F4/80, CD68, and CD11b. In addition, the cells are closely associated with microvessels and structurally intertwined with endothelial cells and pericytes. They constitutively express scavenger receptor classes $\mathrm{A}(1)$ and $\mathrm{B}(1)$, and accumulate blood-borne proteins such as horseradish peroxidase and acetylated low-density lipoprotein (Shi 2010). On further study, we found the PVMs positive for melanocyte marker proteins such as glutathione S-transferase alpha 4 (Gsta4), contain significant amounts of melanin, as well as express Kir 4.1, the fiduciary marker of intermediate cells (Zhang et al. 2012). Thus, we amended the name to reflect this, and PVM cells became perivascular resident macrophagetype melanocytes (PVM/M). According to Cable and Steel (1991), two subclasses of intermediate cells reside in the stria vascularis. Some of intermediate cells interact with strial capillaries through gap junctions (Takeuchi et al. 2001; Takeuchi and Ando 1998). We suspect that the dark melanocyte subclass of these intermediate cells is the equivalent of our PVM/Ms. As a matter of fact, Conlee et al. (1989) gives evidence for a distinction between melanocytes and intermediate cells in cats. Likewise, our studies show that PVM/Ms are a hybrid cell type, including characteristics of both macrophage and melanocyte.

\section{ACKNOWLEDGMENTS}

We thank Ahmed Hassan and John Henry at life Sciences Division, Lawrence Berkeley National Laboratory, Berkeley for their input and guidance in developing workflows for 3D rendering. This work was supported by National Institutes of Health/National Institute on Deafness and Other Communication Disorders Grants DC008888-02A1 (to X.S.), DC008888-02S1 (to X.S.), R01-DC010844 (to X.S.), NIH NIDCD R21-DC12398-01 (to X.R), and NIHP30-DC005983.

Open Access This article is distributed under the terms of the Creative Commons Attribution License which permits any use, distribution, and reproduction in any medium, provided the original author(s) and the source are credited.

\section{REFERENCES}

Al Ahmad A, Gassmann M, Ogunshola OO (2009) Maintaining blood-brain barrier integrity: pericytes perform better than astrocytes during prolonged oxygen deprivation. J Cell Physiol 218(3):612-622

Armulik A, Genove G, Mae M, Nisancioglu MH, Wallgard E, Niaudet C, He L, Norlin J, Lindblom P, Strittmatter K, Johansson BR, Betsholtz C (2010) Pericytes regulate the blood-brain barrier. Nature 468(7323):557-561

Cable J, Steel KP (1991) Identification of two types of melanocyte within the stria vascularis of the mouse inner ear. Pigment Cell Res 4(2):87-101

Cardoso FL, Brites D, Brito MA (2010) Looking at the blood-brain barrier: molecular anatomy and possible investigation approaches. Brain Res Rev 64(2):328-363

Cohen-Salmon M, Regnault B, Cayet N, Caille D, Demuth K, Hardelin JP, Janel N, Meda P, Petit C (2007) Connexin30 deficiency causes instrastrial fluid-blood barrier disruption within the cochlear stria vascularis. Proc Natl Acad Sci U S A 104(15):6229-6234

Conlee JW, Parks TN, Schwartz IR, Creel DJ (1989) Comparative anatomy of melanin pigment in the stria vascularis. Evidence for a distinction between melanocytes and intermediate cells in the cat. Acta Otolaryngol 107(1-2):48-58

DAI M, SHI X (2011) Fibro-vascular coupling in the control of cochlear blood flow. PLoS One 6(6):e20652

Dai M, Yang Y, Omelchenko I, Nuttall AL, Kachelmeier A, Xiu R, ShI $\mathrm{X}$ (2010) Bone marrow cell recruitment mediated by inducible nitric oxide synthase/stromal cell-derived factor-1alpha signaling repairs the acoustically damaged cochlear blood-labyrinth barrier. Am J Pathol 177(6):3089-3099

Gow A, Davies C, Southwood CM, Frolenkov G, Chrustowski M, NG L, Yamauchi D, Marcus DC, Kachar B (2004) Deafness in Claudin 11-null mice reveals the critical contribution of basal cell tight junctions to stria vascularis function. J Neurosci 24(32):70517062

HukeE MJ, Duvall AJ 3RD (1985) Cochlear vessel permeability to horseradish peroxidase in the normal and acoustically traumatized chinchilla: a reevaluation. Ann Otol Rhinol Laryngol 94(3):297-303

JuHn SK (1988) Barrier systems in the inner ear. Acta Otolaryngol Suppl 458:79-83

Juhn SK, Hunter BA, OdLAnd RM (2001) Blood-labyrinth barrier and fluid dynamics of the inner ear. Int Tinnitus J 7(2):72-83

JuHn SK, Ryвak LP (1981) Labyrinthine barriers and cochlear homeostasis. Acta Otolaryngol 91(5-6):529-534

JuHN SK, RYBAK LP, FowlKs WL (1982) Transport characteristics of the blood-perilymph barrier. Am J Otolaryngol 3(6):392-396

Juhn SK, Rybak LP, Prado S (1981) Nature of blood-labyrinth barrier in experimental conditions. Ann Otol Rhinol Laryngol 90(2 Pt 1):135-141 
Kellerhals B (1972) Acoustic trauma and cochlear microcirculation. An experimental and clinical study on pathogenesis and treatment of inner ear lesions after acute noise exposure. Adv Otorhinolaryngol 18:91-168

KIM JH, YU YS, KIm DH, KIm KW (2009) Recruitment of pericytes and astrocytes is closely related to the formation of tight junction in developing retinal vessels. J Neurosci Res 87(3):653-659

Kitajiri S, Miyamoto T, Mineharu A, Sonoda N, Furuse K, Hata M, Sasaki H, Mori Y, Kubota T, Ito J, Furuse M, Tsukita S (2004A) Compartmentalization established by claudin-11-based tight junctions in stria vascularis is required for hearing through generation of endocochlear potential. J Cell Sci 117(Pt 21):5087-5096

Kitajiri SI, Furuse M, Morita K, Saishin-Kiuchi Y, Kido H, Ito J, Tsukita S (2004в) Expression patterns of claudins, tight junction adhesion molecules, in the inner ear. Hear Res 187(1-2):25-34

Klein M, Koedel U, Kastenbauer S, Pfister HW (2008) Nitrogen and oxygen molecules in meningitis-associated labyrinthitis and hearing impairment. Infection 36(1):2-14

Laмm K, ZajIC G, Sснаснт J (1994) Living isolated cells from inner ear vessels: a new approach for studying the regulation of cochlear microcirculation and vascular permeability. Hear Res 81(1-2):83-90

Laurell GF, Teixeira M, Duan M, Sterkers O, Ferrary E (2008) Intact blood-perilymph barrier in the rat after impulse noise trauma. Acta Oto-laryngologica 128(6):608-612

Liu S, Agalliu D, Yu C, Fisher M (2012) The role of pericytes in blood-brain barrier function and stroke. Curr Pharm Des 18 (25):3653-3662

McMenomey SO, Russell NJ, Morton JI, Trune DR (1992) Stria vascularis ultrastructural pathology in the $\mathrm{C} 3 \mathrm{H} / \mathrm{lpr}$ autoimmune strain mouse: a potential mechanism for immune-related hearing loss. Otolaryngol Head Neck Surg 106(3):288-295

Rauch S, Reale E (1968) The pericytes (Rouget cells) of the stria vascularis vessels. Archiv fur klinische und experimentelle Ohren- Nasen- und Kehlkopfheilkunde 192(1):82-90

Rubin LL, Staddon JM (1999) The cell biology of the blood-brain barrier. Annu Rev Neurosci 22:11-28

Sakagami M, Harada T, Sano M, Sakai S, Matsunaga T (1987) Quantitative evaluation of pinocytosis of capillaries of the stria vascularis under normal and experimental conditions. Acta Otolaryngol 103(3-4):189-197

Sakagami M, Matsunaga T, Hashimoto PH (1982) Fine structure and permeability of capillaries in the stria vascularis and spiral ligament of the inner ear of the guinea pig. Cell Tissue Res 226(3):511-522

Sakagami M, Sakai S, Sano M, Harada T, Matsunaga T (1986) Morphological study of the permeability of blood vessels in the modiolus. Nippon Jibiinkoka Gakkai Kaiho 89(2):167-172
Salt AN, Melichar I, Thalmann R (1987) Mechanisms of endocochlear potential generation by stria vascularis. Laryngoscope 97 (8 Pt 1):984-991

Schmutzhard J, Kositz CH, Glueckert R, Schmutzhard E, SchrottFischer A, LACKNER P (2012) Apoptosis of the fibrocytes type 1 in the spiral ligament and blood labyrinth barrier disturbance cause hearing impairment in murine cerebral malaria. Malar J 11:30

SHI X (2009) Cochlear pericyte responses to acoustic trauma and the involvement of hypoxia-inducible factor-1alpha and vascular endothelial growth factor. Am J Pathol 174(5):1692-1704

SHI X (2010) Resident macrophages in the cochlear blood-labyrinth barrier and their renewal via migration of bone-marrow-derived cells. Cell Tissue Res 342(1):21-30

Shi X, Han W, Yamamoto H, Tang W, Lin X, Xiu R, Trune DR, Nuttall AL (2008) The cochlear pericytes. Microcirculation 15 (6):515-29

Suzuki M, Kaga K (1999) Development of blood-labyrinth barrier in the semicircular canal ampulla of the rat. Hear Res 129(1-2):27-34

Suzuki M, Yamasoba T, Ishibashi T, Miller JM, Kaga K (2002) Effect of noise exposure on blood-labyrinth barrier in guinea pigs. Hear Res 164(1-2):12-18

Suzuki M, Yamasoba T, Kaga K (1998) Development of the bloodlabyrinth barrier in the rat. Hear Res 116(1-2):107-112

Tagaya M, Yamazaki M, Teranishi M, Naganawa S, Yoshida T, Otake H, Nakata S, Sone M, Nakashima T (2011) Endolymphatic hydrops and blood-labyrinth barrier in Meniere's disease. Acta Oto-laryngologica 131(5):474-479

TAKeUCHI S, ANDo M (1998) Dye-coupling of melanocytes with endothelial cells and pericytes in the cochlea of gerbils. Cell Tissue Res 293(2):271-275

Takeuchi S, Ando M, Sato T, Kakigi A (2001) Three-dimensional and ultrastructural relationships between intermediate cells and capillaries in the gerbil stria vascularis. Hear Res 155(12):103-112

Yang Y, Dai M, Wilson TM, Omelchenko I, Klimek JE, Wilmarth PA, David LL, Nuttall AL, Gillespie PG, Shi X (2011) Na+/K+ -ATPase alphal identified as an abundant protein in the bloodlabyrinth barrier that plays an essential role in the barrier integrity. PLoS One 6(1):e16547

Zhang W, Dai M, Fridberger A, Hassan A, Degagne J, Neng L, Zhang F, He W, Ren T, Trune D, Auer M, Shi X (2012) Perivascularresident macrophage-like melanocytes in the inner ear are essential for the integrity of the intrastrial fluid-blood barrier. Proc Natl Acad Sci U S A 109(26):10388-10393 